\title{
The Path of the Construction of Sports Culture of Higher Vocational Education Characteristics and Vehicle Design
}

\author{
Xiaoyan Yang \\ Sichuan College of Architectural Technology \\ De Yang, Sichuan Province 618000,China \\ e-mail: 279335582@qq.com
}

\begin{abstract}
Because the campus culture can have a extremely important impact on the whole school education, as an important part of campus culture, campus sports culture can play an important role in cultivating students' quality and development of school sports, corresponding to the higher vocational education campus sports culture which is belong to the whole higher vocational campus culture is an important content and part of the vocational college campus sports culture, with its because of the unique cultural atmosphere in the midst of intangible and tangible have great impact to the masses of teachers and students, make the build out of the campus sports culture atmosphere with unique ingredients in higher vocational colleges, higher vocational colleges of all the students are actively involved in sports, reveals the construction process of campus culture in higher vocational colleges, the sports motivation role in the process of shaping talents, which gives new meaning to sports. This research will focus on in this paper, the connotation and function of campus sports culture and the current situation of higher vocational colleges and universities sports culture, and campus sports culture construction in higher vocational colleges put forward corresponding countermeasures.
\end{abstract}

Keywords- higher vocational education; Sports culture construction; Characteristic; The path

\section{THE BASIC CONNOTATION, THE CAMPUS SPORTS CULTURE THEORY}

\section{A. Sports culture}

By definition, culture is refers to the humanity in the long-term social and historical development of material and spiritual wealth created by the sum of the culture will be into spiritual culture and material culture are the two aspects of content, but we only study of spiritual culture, spiritual culture that is in the development process of human spiritual wealth of all creation. Culture from a narrow sense, that is to say has obvious difference about religion with politics, economy, culture, art, sports, health, ethics, philosophy, education, science, theory of spiritual culture. Because of this, can be obtained through the above analysis, in essence, this sport is also belongs to a kind of culture, in addition, can also be within the category of sports culture comes down to sports culture, this is all human beings have created splendid culture heritage treasure house of the extremely important part of the content, so it is also belong to spiritual culture, which is about the contents of sports culture development effectively.

\section{B. Campus sports culture}

Through the above effective definition for the concept of sports culture, which will lay a foundation for the definition of campus sports culture, the campus sports culture is a scope limitation schools this specific range, effectively rendering with specific sports culture atmosphere. Through defining the definition of campus sports culture means that people in the process of scientific research and teaching practice about sports to created the material wealth and spiritual wealth combined. Is the teachers' colleges and universities, in other words, students and staff in the sports competitions, sports teaching, the construction of sports facilities, fitness and other sports activities do all spiritual wealth and material wealth with form, at the same time, also contains the related concept of sports consciousness and sports. Campus sports culture is to students as the main body, the main content is the sports culture activities, usually the main space is defined as the campus, the main characteristics is the campus spiritual culture of a group. Through the study found that have a certain specificity, the cultural atmosphere which is with the school's way of life, and training goal achieve effective school spirits and disciplines. Campus sports culture, this kind of cultural phenomenon with distinctive rich denotation and connotation profoundly, which makes the campus sports culture and aesthetic education, intellectual education and moral education form a complete group of campus culture, at the same time, it also with mass sports culture, sports culture to build become generalized sports culture of the group.

Due to the campus sports culture, this can be summed up in a social and cultural forms, has its personality is especially strong, from the source view, the campus sports culture which comes from the social culture, the background is the social culture, although it is breeding in society, but this is definitely not to be simply equated with social culture of a kind of special cultural form 。 It to be because of this, the campus sports culture has its own special features. Usually, campus spirit that is the core and soul of campus sports culture, essentially, campus spirit this group belongs to deep consciousness, at the same time or group cohesion and centripetal force, or the entire campus community in the common behavior way, value orientation, psychological 
characteristics and value identity. Just because of this, part of people will become the academic culture appropriate metaphor campus spiritual culture, and the sports culture gradually developed into the construction of campus spirit of a means of form and constitute an integral part of the content of campus culture.

\section{The role of campus sports culture}

Generally, in the whole campus culture, the important part of sports culture. Is in the school campus sports culture this kind of culture form the existence of a specific environment. After summarizing extracted the essence of sports spirit is confident more than, solidarity and collaboration, unyielding, fair competition, for a long time, through the unique role and charm for the development of students' physical and mental health plays the subtle influence of extremely powerful, and it gradually developed a window shows campus culture domestically and abroad. Olympic spirit emphasizes the fair competition, progress, friendship, unity, stronger, higher, faster, and it is important in the participation idea, has the charm is in the background of sports culture in deep. Throughout the campus culture for the people has a more far-reaching influence, the most widely, the most active, the duration of the longest, the largest number of participation in cultural activities is sports and sports culture.

From the content point of view, this is cultural atmosphere for the school campus sports culture and the cultural atmosphere to create one of the most important and absolutely cannot lack, and it is also the most powerful catalysts to promote campus cultural development. As the main carrier of the development of sports culture is sports, the role of not only confined to the physical fitness enhancement, to improve health, is even more crucial in developing the sports of a respected by unity cooperation, fair competition of morality; Is also a kind of spirit do cooperate and communicate with each other; Is also a kind of self-confidence, respect yourself, more than an unyielding, respect other people's moral quality, overall, this is what we strive for current humanistic spirit. Embodied from the content point of view, the campus sports culture which not only has a lively and active, healthy and progressive campus culture construction, reflected for a healthy way to spread, also can cultivate one's morality raises a gender, the sports knowledge greatly, so that they can give students build a for their own special skill and talent to full display of the platform. Is one of the most critical with rich and colorful activities, room get to cultivate students' ability of organization, to effectively enhance students' participation awareness, effectively promote the formation of students' emotional attitude values and perfect personality, so that the moral cultivation in higher vocational college students get a boost. Is affected by the campus sports culture to carry forward the positive, in the struggle process of ecstasy, make students get edify sentiment, the character will get exercise, personality to do sublimation, also can purify the hearts of students. And it has a very active role in promoting students' physical and mental health.
Due to spread sports culture that is to conform to the social development of humanity spirit to carry forward. Campus sports culture is the spirit force will maintain school groups, play an important role to human atmosphere and school culture construction, promote the spiritual civilization construction and campus spiritual culture. Can be seen from this, want to do make full use of sports culture resources, people-oriented, so that they can make all the teachers and students actively participate in the campus sports culture activities, actively do for society to understand and to contact the society, makes students advocating rational, forge ahead, unity, cooperation, respect the facts, the indomitable spirit to develop, so as to fully implement quality education.

\section{Current status of sports culture in higher vocational} colleges.

As the core part of the campus sports culture is the campus sports spiritual culture, it also belongs to the vocational college students of sports ideology and spiritual way of life, which makes it a particularly profound and rich connotations. By comparing among higher vocational colleges to establish good campus sports culture atmosphere, this can let yourself in all members of this group relies on imitation, under the guidance of observation or by other members in order to do it to obtain useful information, so that they can have aesthetic temperament and interest, sports thinking, emotional way and behavior habits, and to finally form a specific campus sports culture and tradition, carry forward and strengthen the good campus sports culture, essentially, this is also the purpose of the construction of campus sports culture and core. Can be seen from this, the investigation and analysis of the status quo of higher vocational college campus sports spiritual culture spirit should be based on sports knowledge, sports, fashion, ideas and so on several aspects of implementation from the perspective of a current situation, has gradually perfect the campus sports culture construction in vocational college, but in this process, also has many problems exist in the construction of system culture, spiritual culture and material culture. Through the perspective of the history of higher vocational the evolution from technical secondary school education, so there is necessity to do improve a lot of sports rules and regulations, should also further the implementation of the relevant documents and regulations of the ministry of education.

Based on the current view, the main task of the vocational colleges campus sports culture construction is the construction of sports facilities, sports culture environment construction. Did to this issue through the study found, which reflects the absolute isn't just a matter of money, but more should put the focus on the person's subjective initiative of the play up and update.

Aim from the point of view, the campus sports culture is a must for students with lifelong sports consciousness, but from the point of objective reality, the current serious lack of teachers for students lifelong sports consciousness of guidance, the emphasis is on keeping fit and technical 
guidance, and for life is engaged in the importance of physical exercise.

And from the point of participating in sports activities in the way, the students in the main way is together with friends and classmates, according to the results of this, this has a lower school sports club or association, corporate development level, and students participate in school sports club's subjective consciousness is more bad. In this process, will also be able to objectively reflect the colorful club activities from the content point of view is not enough, lack of necessary energy makes the whole club. Formed by all duty, all build atmosphere did not do.

\section{The CurRent New Situation OF Higher}

VOCATIONAL COLLEGES AND UNIVERSITIES SPORTS CUlTuRE FOR THE CONSTRUCTION OF THE PATH AND THE

\section{CHOICE OF CARRIER}

1、 Is a must to reciprocate employee training work, make teachers' consciousness of campus sports culture. Due to the definition of campus sports culture consciousness is analyzed, it is refers to the corresponding vocational colleges in order to do to achieve the goals of education, to do for people's code of conduct, fitness goals, beliefs, traditional sports group consciousness, morality and ideal and values are concentrated reflection. Makes sports culture which is formed by the group consciousness and values are relatively unified, vocational colleges should also be training on campus sports culture consciousness be strengthened, effectively to pass in the process of schoolbased training held on a regular basis, will the school sports related culture, sports, work, work plan, etc are included, with regularly conducted training and study, so can let all the teachers in higher vocational colleges of profile control of consciousness will clear understand that for students physical fitness enhancement, to effectively promote the healthy growth of students, this is the future of whole nations and peoples, teachers by making students exercise an hour every day, health work for fifty years, a happy life for a lifetime, made of such ideas into the students' heart, to do the physical exercise as a conscious behavior of all the teachers and students in higher vocational colleges 。

2、 Is through the effective development of sports school-based teaching materials, makes building mode of classroom teaching has unique characteristics. Because of the higher vocational colleges and universities sports culture construction is the main channel of physical education, from the perspective on the one hand, students with sports teaching will be including aspects such as morality, thoughts and ideas education to accept; On the other hand, due to the body of the school physical education is students, higher vocational education of physical education through organizational implementation of physical education for students, so that it can let students about sports knowledge in the whole during the period of school to compare systems and comprehensive grasp, for sports culture to fully understand, let all students to actively participate in sports activities, make school sports culture fundamentally get effective guarantee. As since in recent years, our country's various vocational colleges by combining with the objective reality and the characteristics of higher vocational, develop school-based teaching material of high vocational schools to expand training, also it has close relationship with the student's physical quality professional development of university-based curriculum of open, base on the background of national curriculum standard, in addition, when adding certain amount of hours sports school-based course, this makes the students get a great rich sports teaching content, make the learning interest of student sports activities have obvious improve, which lay a solid foundation for the students to obtain employment after graduation.

3、Is to make the extracurricular sports activities have obvious personality of students. Carried out on the role of it, the extracurricular sports activities not only you have the completed for quality sports and sports skills practice, at the same time, also can do effective active for the content of the campus sports culture, promote students' enthusiasm to participate in sports activities, apart from higher vocational colleges according to the relevant provisions of the state to offer PE, can also according to the students' interests and characteristics, the corresponding open three chess, taekwondo, badminton, table tennis, rhythmic gymnastics, roller skating, football, basketball, dole interest group activities, from the activity's content view, which is more than just personal projects, there is a certain collective project; Not only has a student project, there is a certain teacher of projects; Which not only has acting project, and the race. That makes students involved in the activities, one hundred percent under a variety of forms, do sports clubs, associations, groups of students, such as the establishment and perfection of organization, let the student's backbone role into full play, it is in higher vocational colleges and universities extracurricular sports clubs appear is imperative in our country, to give the school authorities give high attention and leadership, through the creation of the conditions in order to ensure that students have enough venue and time for the club's activities, making schools according to their own objective reality come out a new way has its own characteristics, which has a better activity is to carry out sports culture festival, and this makes the makes the festival has gradually developed into the heart of all the teachers and students of the festival and event, this needs to be further in practice and improve, enrich and approach to exploring the sports culture festival, content, form, and the inherent law, through the good sports culture construction actively, so as to enhance the students' basic knowledge and sports health consciousness and improve sports skills, physical exercise habit gradually.

Due to one of the main platforms of the masses of teachers and students to carry out sports activities is the school campus, through to the high vocational college campus sports culture construction actively, make are fully mobilize all positive factors, the material as the foundation of environmental construction, do careful organization of cultural activities, among participating in sports activities is perfect, in the perfecting process of implementation, mulberry heart makes traditional features with its own style 
of the campus sports culture to form, the real implementation of the concept of health first, to the school quality education gradually to the new situation.

\section{REFERENCES}

[1] MeiJiPing On the socialist core values guide vocational colleges culture construction thought[J]. China vocational and technical education. 2011 (36)
[2] YanChuHua 、 Peng yuan. Cultivation of "four good" culture promote educational quality-_Hunan transportation vocational technical college) Ten years of exploration and practice in "Four good"cultural development[J]. China's vocational and technical education. 2011 (35)

[3]. Zhou Jiansong Thinking about building the modern vocational education system $[\mathrm{J}]$. China's higher education research. 2011 (7) 